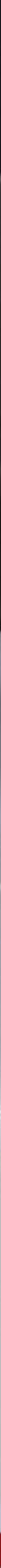




\section{Obtaining additional information by using exercise testing in the laboratory in the diagnosis of asthma}

T. Stensrud ${ }^{1,2}$

${ }^{1}$ Norwegian School of Sport Sciences, Oslo, Norway, and ${ }^{2}$ ORAACLE (the Oslo Research group for Asthma and Allergy in Childhood; the Lung and Environment), which is a member of the GA2LEN, European Network of Centres of Excellence.

\section{Correspondence}

T. Stensrud

Norwegian School of Sport

Sciences

P.0. Box 4014 Ullevaal Stadion, N0-0806 Oslo

Norway

trine.Stensrud@nih.no

\section{Provenance}

Commissioned article, peer reviewed. assessment of EIB and $\mathrm{V}^{\prime} \mathrm{O}_{2}$,peak into one EIB test protocol, even though the gold standard in assessment of $\mathrm{V}^{\prime} \mathrm{O}_{2}$, peak is an incremental protocol. Additional and useful information about asthma can be obtained and differential diagnoses to EIB can be assessed by measuring different physiological variables during the EIB challenge. The following article will focus on the advantages of measuring exercise capacity during an EIB test, after a short discussion of different test protocols and ergometers.

Exercise-induced bronchoconstriction (EIB)

influences daily life activities and sports activities in children, adolescents and adults. To enable optimal choice of treatment, an accurate assessment of EIB is therefore important. EIB consists of bronchoconstriction occurring immediately or soon after physical exertion [1-3], and is best assessed by a standardised exercise test. Running on a treadmill for 6-8 min at a submaximal work load is a commonly used test $[4,5]$. Lately it has been maintained that an exercise load corresponding to $95 \%$ of maximum heart rate (HRmax) is preferable to obtain a high sensitivity [3].

Elite athletes are more likely to report asthma and asthma symptoms than age- matched controls. The prevalence of asthma and bronchial hyperresponsiveness (BHR) is higher among elite athletes assessed both by questionnaire and objective measurements [6-9]. On the other hand, it is known that reduced physical fitness and physical activity are important for the development of chronic disorders, including asthma $[10,11]$. Increasing prevalence of overweight, obesity $[12]$ and asthma $[13,14]$ in children and adolescents is reported, and a number of longitudinal studies have reported increasing risk of developing new asthma or asthma symptoms in obese children and adolescents [15-18]. It was recently suggested that the lack of physical activity, more than the obesity itself, increases the risk of asthma [19].
HERMES syllabus link: modules B.1.1, B.1.10, D.1.6 
An individual's pattern of physical activity and future activity level is often founded during childhood and adolescence. Assessment of physical fitness may give important information about physical functioning in patients with chronic lung disorders, including asthma.

\section{Test protocols and ergometers}

The choice of test protocol and ergometer should be based on the purpose of the exercise test and the patients performing the tests: children, adults, elite athletes, and untrained or obese patients. If the reason is to provoke EIB, an EIB test will be used. If the purpose is to measure physical fitness, an incremental test protocol is commonly used.

As asthma is a limiting factor for participation in physical activity and sport, assessment of physical fitness may give important information about physical functioning. Physical fitness is an umbrella concept covering a series of qualities related to the performance of physical activity [34], with permission from the publisher.
[20]. Maximum oxygen uptake $\left(\mathrm{VO}_{2}\right.$,max $)$ or peak oxygen uptake $\left(\mathrm{VO}_{2}\right.$,peak) is widely recognised as one of the most important measures of aerobic capacity and physical fitness $[20,21] . \mathrm{VO}_{2}$, max provides an accurate measure of aerobic power, and it is highly related to cardiac output. ÁsTRAND et al. [20] define $\mathrm{VO}_{2}$, max as the achievement of a plateau or "levelling off" in oxygen uptake $\left(\mathrm{VO}_{2}\right)$ despite continued increase in workload ( $<2 \mathrm{~mL}$ per $\mathrm{kg}$ per min rise in $\left.\mathrm{VO}_{2}\right)$, to be the most important criterion to estimate $\mathrm{V}_{2}$, max. Other factors indicating achievement of $\mathrm{VO}_{2}$, $\max$ are respiratory exchange ratio (RER) $\geq 1.05$ and heart rate $(\mathrm{HR}) \geq 95 \%$ of HRmax (based on 220 beats per min - age in yrs). In young subjects, this levelling off does not occur, and $V^{\prime} \mathrm{O}_{2}$, max may be determined as $\mathrm{VO}_{2}$,peak, the highest recorded $\mathrm{V}_{2}$ during the exercise test [22-25].

The choice of exercise ergometer and test protocols may influence the $\mathrm{V}_{2}$, peak values both in children and in adults: treadmill running or cycling are the type of exercise most commonly used [20]. Åstrand et al. [20] conclude that treadmill running is the best exercise ergometer for testing healthy people, especially children, because walking or running is the natural way to move and demands dynamic use of large groups of muscles. Exercise testing for athletes may be performed within the athletes' own discipline of the athletes, as exemplified for swimmers [26]. A rowing ergometer has been employed in fitness testing of children [27]. Special considerations need to be taken into account for children, related to age, sex, growth and physical performance. It has been maintained that in children it is preferable to employ running rather than cycling in testing [28].

Previous studies have compared different test protocols for assessing $\mathrm{V}^{\prime} \mathrm{O}_{2}$,peak both in children and in adults. In spite of a general consensus that an incremental test protocol lasting between 8-12 min will elicit the highest $\mathrm{VO}_{2}$,peak with the lowest perception of difficulty and discomfort, studies have not found a difference in $\mathrm{V}^{\prime} \mathrm{O}_{2}$,peak between different test protocols [29, 30]. DAY et al. [31] concluded that $\mathrm{VO}_{2}$, peak was not different with a constant workload protocol lasting between 4-10 minutes as compared to an incremental ramp protocol. Rossirer et al. [32] suggested that $\mathrm{VO}_{2}$, peak can be reached at a constant workload corresponding to $105 \%$ as well as $95 \%$ of maximum workload. This is in agreement with COOPER [33] who maintained that short bouts of high-intensity exercise are the physiological way of studying children, rather than repeated stepwise exercise testing. Different test protocols may 
be needed to assess physical fitness in children and adolescents with different diseases. Whereas a gradual increase in speed and inclination of the treadmill may be beneficial for subjects with cardiac diseases, a more rapidly increasing protocol may be better suited for asthmatic children and adolescents [33].

Until now, assessments of EIB and $\mathrm{VO}_{2}$,peak have been performed with two different test protocols on separate days. One study has shown the possibility of combining assessment of EIB and $\mathrm{VO}_{2}$,peak into one exercise test [34]. STENSRUD and CARISEN [34] compared $\mathrm{VO}_{2}$,peak by applying an EIB test protocol and a stepwise protocol and conclude that neither $V^{\prime} \mathrm{O}_{2}$,peak nor peak minute ventilation ( $V$ E,peak) differed between the two protocols (fig. 1) and thus gave useful information about both EIB and physical fitness.

The EIB test in the study of STENSRUD and CARLSEN [34], was performed at two different inclinations of the treadmill, 5.3\% and $10.5 \%$. Subjects ran for 8 min without warming up. The starting running speed was approximately $70-80 \%$ of estimated HRpeak. The speed was subsequently adjusted during the first 4 min to achieve a workload corresponding to the maximum speed the subjects were able to sustain during the last 4 min: about $95 \%$ of estimated HRpeak. $V^{\prime} \mathrm{O}_{2}, V^{\prime} \mathrm{E}, \mathrm{RER}$, respiratory frequency $(f \mathrm{R})$ and $\mathrm{HR}$ were measured during the EIB test. Lung function was measured by maximal forced expiratory flow volume loops before and 1, 3, 6, 10 and 15 minutes after the test.

The stepwise protocol for measuring $\mathrm{V}^{\prime} \mathrm{O}_{2}$,peak was according to the procedure described and validated by Hermansen [35] and Åstrand et al. [20] and consisted of 20 min warm-up at a workload corresponding to approximately $50-60 \%$ of $\mathrm{VO}_{2}$,peak. After warming up, the running speed was increased to a workload of $\sim 80 \%$ of $\mathrm{VO}_{2}$,peak and further increased every minute until the subjects were close to exhaustion after about 4-6 min. $\mathrm{VO}_{2}, V^{\prime} \mathrm{E}, \mathrm{RER}, \mathrm{fR}$ and HR were measured during the test and the criteria to identify $\mathrm{V}^{\prime} \mathrm{O}_{2}$, peak were used.

Even though no significant differences in $V^{\prime} O_{2}$,peak or $V_{E}$,peak were found, it should be remembered that the results may not apply to all asthmatic subjects. Anti-asthmatic treatment has to be withheld before EIB testing according to European Respiratory Society and American Thoracic Society guidelines $[2,36]$, and this may influence $\mathrm{VO}_{2}$,peak if bronchoconstriction occurs during the test. However, several previous studies have shown that bronchoconstriction occurs soon after a 6-8 min exercise test and not during the exercise [1-3, 36], and $\mathrm{V}^{\prime} \mathrm{O}_{2}$,peak may thus not be affected. If bronchoconstriction occurs during the exercise test $V^{\prime} \mathrm{O}_{2}$,peak may be affected and a new test for measuring $V^{\prime} \mathrm{O}_{2}$,peak with pre-medication may be performed.

However, assessment of EIB and $V^{\prime} \mathrm{O}_{2}$,peak in a single test may reduce the burden for the patient by saving one test day; simplify diagnostic and monitoring procedures of the patients and the costs for the health system. The following text will therefore focus on the assessment of EIB and exercise capacity by using an EIB test protocol.

When performing an EIB test or a test for assessment of $\mathrm{V}^{\prime} \mathrm{O}_{2}$, peak at a fixed inclination of the treadmill, it is common to use an inclination of $3^{\circ}$ or $5.3 \%$ for children, untrained subjects and athletes $[2,25]$. As regards athletes within endurance sports, with the exception of runners, both EIB tests and $V^{\prime} \mathrm{O}_{2}$, max tests are usually performed at $6^{\circ}$ or $10.5 \%$ inclination to minimise the effects of seasonal changes in $\mathrm{V}^{\prime} \mathrm{O}_{2}$, max caused by changes in running technique and running economy as a consequence of seasonal shifts in the type of training, e.g. running and skiing [37]. On the other hand, a steep inclination can cause local fatigue in the thigh and leg muscles, thus limiting the achievement of $V^{\prime} \mathrm{O}_{2}$,peak, especially in children and untrained subjects [38].

Peak oxygen uptake, presented as $\mathrm{mL}$ per $\mathrm{kg}$ per min, is the best measure of physical fitness or exercise capacity and a good predictor of the subject's potential to move and lift the body, but it does not reflect cardiac performance [20]. The total oxygen uptake (L per min) correlates with cardiac output, myocardial oxygen consumption and blood flow and both measures are thus useful [20].

\section{Pulmonary hyperinflation}

Assessment of physiological variables other than $V^{\prime} \mathrm{O}_{2}$,peak and HR during an EIB test may be useful. $V^{\prime}$ E,peak, $f R, R E R$ and arterial oxygen saturation $\left(\mathrm{S}, \mathrm{O}_{2}\right)$ may give valuable information about dynamic hyperinflation and breathing pattern and be helpful in the diagnosis of differential diagnosis to EIB.

Pulmonary hyperinflation or dynamic hyperinflation is usually defined as an abnormal increase in functional residual capacity (FRC), for example volume at the end of a tidal expiration [39]. This is seen in patients with obstructive pulmonary diseases, including asthma. With increased airway obstruction causing increased resistance 


\section{Educational questions}

1. Is it possible to assess EIB and exercise capacity ( $\mathrm{VO}_{2}$,peak) by applying the same test protocol? 2. Which ergometer is the first choice in testing:

a) Asthmatic children?

b) Untrained adults?

c) Athletes?

3. What kind of valuable information can be obtained by measuring exercise capacity during exercise in asthmatic patients?

4. What kind of additional information regarding differential diagnosis to EIB can be assessed during an exercise test?

5. What is the usefulness of assessing tidal breathing loops and breathing reserve during exercise?

6. How do different climatic conditions influence EIB and exercise capacity? to air flow, the lung may not have enough time to empty before the next inhaled breath and $f_{R}$ will thus increase to maintain the ventilatory demand. Rapid breathing, for any reason, will trigger this vicious response, and even a mild episode of increased dyspnoea may result in anxiousness and fear leading to the rescue breathing pattern and rapidly making the dyspnoea worse. Learning to recognise and control the emotional aspects of the breathing pattern may help to control breathing.

$f_{R}$ and RER may give helpful information about abnormal breathing pattern. Patients with EIB are reported to breathe faster during exercise in cold air than in normal indoor conditions and deeper and slower during exercise in humid air $[40,41]$. It has been observed that patients with additional diagnoses to asthma, such as anxiety, eating disorders and obesity, show an abnormal breathing pattern during exercise. Obesity itself is a common cause of breathlessness on exertion and it probably acts synergistically with airway obstruction in the generation of breathlessness [42]. FRC is reduced in obese patients, due to abdominal fat tissue contents on the position of diaphragm, resulting in reduced expiratory reserve volume $[20,42]$.

\section{Differential diagnosis to EIB}

Exercise induced laryngeal stridor (EILS) is a frequent differential diagnosis to EIB and the condition is most often seen in young well-trained girls participating in endurance sports. The prevalence in athletes is reported to be 5.1\% [39]. In 2004 STENSRUD and CARLSEN [43] reported a prevalence of $17.5 \%$ in athletes referred to a pulmonary clinic with exercise-induced respiratory symptoms. The symptoms of EILS are inspiratory stridor occurring during maximum exercise and stopping when exercise is terminated. During exercise, audible inspiratory sounds can be heard from the laryngeal area, with no effect of bronchodilators or other asthma medication. Hyperventilation is often seen in relation to EILS and measurement of $V^{\prime} E$ (which often shows a sudden drop close to maximum), $V^{\prime} \mathrm{O}_{2}, f R$ and RER during exercise may serve as an additional tool to confirm the diagnosis of EILS. The correct diagnosis of EILS should be confirmed by direct fibreoptic laryngoscope during exercise.
Another differential diagnosis related to EIB is exercise-induced arterial hypoxaemia (EIAH). DeMPSEY et al. [44] reported a prevalence of 50\% in elite male runners [45]. EIAH is defined by a reduction in $\mathrm{Sa}_{1} \mathrm{O}_{2}$ of $8-10 \%$ from before to after strenuous exercise [46]. This occurs especially in highly endurance-trained athletes and is thought to be primarily due to diffusion limitations and/ or ventilation/perfusion mismatch [47].

Elite athletes are also at risk of "overtraining" and this condition may sometimes represent a possible differential diagnosis to EIB.

If an athlete complains about respiratory symptoms during exercise and no bronchial hyperresponsiveness or EIB is found, one of the above conditions is a possible cause.

On the other hand, poor physical fitness in contrast to enthusiastic parental expectations is a frequent occurrence among children and adolescents participating in sports and can easily be assessed by measuring exercise capacity.

\section{Assessment of breathing reserve and tidal breathing during exercise}

In patients with obstructive chronic respiratory disorders, including asthma, assessment of physical fitness may give important information of the severity of illness and the ability to master physical exercise. Particularly important information can be obtained when this type of testing is combined with measurements of breathing reserve (BR), made by measuring maximal voluntary ventilation before exercise and comparing it to $V^{\prime}$ E,peak achieved during exercise. The difference in is defined as BR: normal BR in healthy subjects is $20-40 \%$ [20].

The tidal breathing loops obtained during exercise, most often during running on a treadmill, are related to the maximal expiratory flowvolume loops obtained before running $[48,49]$. Limitations in physical fitness may be set by the baseline lung function, and assessment of flow limitation and end-expiratory lung volume during exercise may give important information about the possible training effect that may be obtained [50]. The simultaneous assessment of tidal breathing loops during exercise and assessment of $B R$ is useful to show the patient whether there is a pulmonary limitation. 


\section{EIB and exercise capacity in different climatic conditions}

More knowledge about different climatic conditions in relation to EIB and exercise capacity is needed in order to give optimal training advice and treatment to asthmatic patients in relation to physical activity. Elite athletes often practise altitude training in unfavourable environments. More knowledge is also needed in relationship to regular physical training of asthmatic subjects, especially in countries with sub-Arctic climates, where the winter season can be quite cold. Furthermore it is not unusual for children and adults to take part in activities such as mountain-climbing, skiing and tracking in medium or higher altitudes where atmospheric pressure is lower than at sea level.

It is known that cold, dry air increases EIB, and that humid air reduces EIB in subjects with asthma (fig. 2) [51-54]. However, few studies exist concerning the effect of different climatic conditions upon exercise capacity in subjects suffering from EIB, and these studies have given conflicting results [55-57]. Hypoxic gas inhalation has been reported to enhance bronchial hyperresponsiveness and result in bronchoconstriction in some animal models, and in humans with asthma $[58,59]$. The data on humans have so far been conflicting $[60,61]$. Several authors have, on the other hand, reported reduced exercise capacity in healthy, trained and untrained subjects in a hypobaric environment due to reduced $\mathrm{Sa}_{1} \mathrm{O}_{2}[62,63]$.

The few studies that have been carried out to investigate the influence of cold and humid air upon exercise capacity in asthmatic subjects have shown conflicting results [40, 41, 55-57]. Only in three studies have the authors reported on $V^{\prime} \mathrm{O}_{2}$, max $[40,41,57]$. The inclusion criteria, test protocols and choice of ergometer vary between the studies, and the results are thus difficult to compare. Most studies also include few subjects. KaLuncs et al. [55] did not find any differences in $V^{\prime} \mathrm{O}_{2}$ or in other physiological variables in asthmatic subjects during exercise in room-temperature conditions when inhaling cold, dry air compared with warm, humid air. SANDSUND et al. [57] found no differences in $V^{\prime} \mathrm{O}_{2}$ at submaximal workloads, in $\mathrm{V}^{\prime} \mathrm{O}_{2}$, max or in lung function in seven mildly asthmatic subjects between inhaling cold air and warm air during exercise in a cold environment. EsCHENBACHER et al. [56] found that the workload in watts per $L$ per min of oxygen consumed was significantly greater with cold and dry

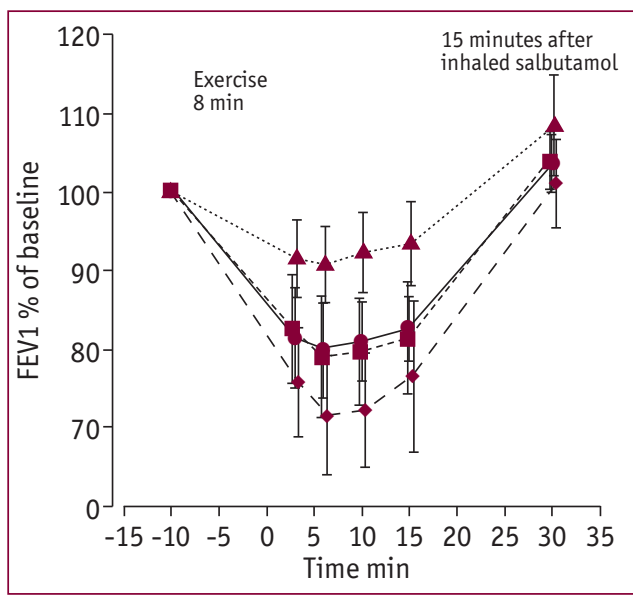

conditions compared with hot and humid conditions in eight male asthmatic subjects. STENSRUD and co-workers $[40,41]$ concluded that $V^{\prime} O_{2}$,peak was reduced in cold air and increased in humid air compared to a normobaric environment in subjects with diagnosed EIB (fig. 3).

The effect of cold air upon physiological variables such as $V^{\prime} O_{2}, V^{\prime} E$ and $H R$ in healthy subjects is reported to vary depending on factors such as type, intensity and duration of exercise, amount of fatty tissue, wind, ambient temperature, clothing, fluctuations in body temperature and energy reserves [64]. In eight healthy males Quirion et al. [64] found significantly reduced $\mathrm{V}^{\prime} \mathrm{O}_{2}$, max, maximum workload and time to exhaustion whereas $V^{\prime} E$ did not change during a short exhaustive exercise at $-20^{\circ} \mathrm{C}$ and $0^{\circ} \mathrm{C}$ compared with $20^{\circ} \mathrm{C}$. SANDSUND et al. [65] reported increased $V^{\prime} \mathrm{E}$ and $V^{\prime} \mathrm{O}_{2}$ at submaximal workloads in an environment of $-15^{\circ} \mathrm{C}$ versus $23^{\circ} \mathrm{C}$, whereas no difference was found for $\mathrm{V}^{\prime} \mathrm{O}_{2}$ max. They suggested that the exercise stress increased in a cold environment, probably as a response to increased metabolic demand. Their findings in healthy subjects are supported by CLAREMonT et al. [66].

Regarding exercise capacity in a hypobaric environment, only one study known to the present author has looked at $V^{\prime} O_{2}$,peak in subjects with

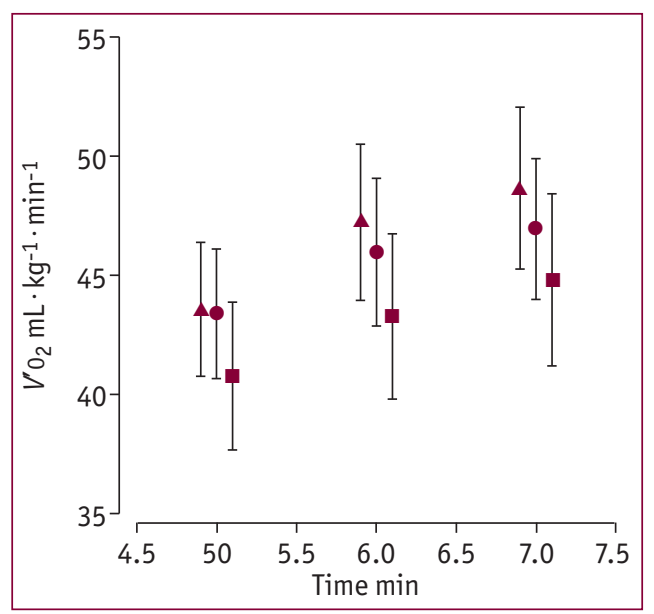

Figure 2

Lung function (FEV 1 ) before and 3,6,10 and 15 minutes after exercise and 15 minutes after inhaled salbutamol in normobaric (circles), hypobaric (squares), cold (diamonds) and humid (triangles) environments. Results are given as mean with $95 \%$ confidence intervals $(n=20)$.

\section{Figure 3}

Oxygen uptake measured in the last 3 min of an EIB test in normobaric (circles), cold (squares) and humid (triangles) environment. Results are given as mean with $95 \%$ confidence intervals $(n=20)$. 
EIB. BernTSEN et al. [67] reported no changes in EIB after exercising in a hypobaric environment (fig. 2) compared with a normobaric environment, but a reduction in $\mathrm{V}^{\prime} \mathrm{O}_{2}$,peak of $10.1 \%$ in hypoxia most probably due to the lower $\mathrm{Sa}_{1} \mathrm{O}_{2}$ in the hypobaric environment. However, several authors have investigated how a reduced barometric pressure affects $\mathrm{V}^{\prime} \mathrm{O}_{2}$, max in healthy trained and untrained subjects $[62,63,68]$. "Untrained" healthy subjects $\left(V^{\prime} \mathrm{O}_{2}\right.$, max $\leq 60 \mathrm{~mL}$ per $\mathrm{kg}$ per $\left.\mathrm{min}\right)$ are reported to have a $3.6 \%$ reduction in $V^{\prime} O_{2}$,peak per $1,000 \mathrm{~m}$ of increased altitude, while "trained" healthy subjects $\left(V^{\prime} \mathrm{O}_{2}\right.$, max $\geq 60 \mathrm{~mL}$ per $\mathrm{kg}$ per $\left.\mathrm{min}\right)$ are reported to have a $6.5 \%$ reduction $[62,63]$. The larger drop in $V^{\prime} \mathrm{O}_{2}$, max in a hypobaric environment in athletes, who are more fit, could be explained by diffusion limitation at these high work rates [69].

\section{Conclusion}

In conclusion, an ElB test protocol can be used for both provoking EIB and for assessing exercise capacity. Physiological variables measured during the exercise challenge may give additional and valuable information about the asthma disease and how the patients master their disease. Additional diagnosis or differential diagnosis to EIB may also be assessed by measuring exercise capacity.

\section{References}

1. Anderson SD. Exercise-induced asthma: stimulus, mechanism and management. In: Barnes PJ, Roger IW, Thomson NC, eds. Asthma. Basic Mechanisms and Clinical Management. London, Academic Press, 1988; pp. 503-522.

2. European Respiratory Society. Clinical exercise testing with reference to lung diseases: indications, standardization and interpretation strategies. ERS Task Force on Standardization of Clinical Exercise Testing. Eur Respir J 1997; 10: 2662-2689.

3. Carlsen KH, Engh G, Mørk M. Exercise induced bronchoconstriction depends on exercise load. Respir Med 2000; 94: 750-755.

4. Sterk PJ, Fabbri LM, Quanjer PH, et al. Airway responsiveness: standardised challenge testing with pharmacological, physical and sensitizing stimuli in adults. Eur Respir J 1993; 6: Suppl. 16, 53-83.

5. Anderson SD, Connolly NM, Godfrey S. Comparison of bronchoconstriction induced by cycling and running. Thorax 1971; 26: 396-401.

6. Heir T, Oseid S. Self-reported asthma and exercise-induced asthma symptoms in high-level competetive cross-country skiers. Scand J Med Sci Sports 1994; 4 : 128-133.

7. Sue-Chu M, Larsson L, Bjermer L. Prevalence of asthma in young cross-country skiers in central Scandinavia: differences between Norway and Sweden. Respir Med 1996; 90: 99-105.

8. Stensrud T, Mykland KV, Gabrielsen K, et al. Bronchial hyperresponsiveness in skiers: field test versus methacholine provocation? Med Sci Sports Exerc 2007; 39: 1681-1686.

9. Rundell KW, Im J, Mayers LB, et al. Self-reported symptoms and exercise-induced asthma in the elite athlete. Med Sci Sports Exerc 2001; 33: 208-213.

10. Smith GD, Shipley MJ, Batty GD, et al. Physical activity and cause-specific mortality in the Whitehall study. Public Health 2000; 114: 308-315.

11. Anderssen S, Holme I, Urdal P, et al. Diet and exercise intervention have favourable effects on blood pressure in mild hypertensives: the 0slo Diet and Exercise Study (ODES). Blood Press 1995; 4: 343-349.

12. Juliusson PB, Roelants M, Eide GE, et al. Overweight and obesity in Norwegian children: secular trends in weight-for-height and skinfolds. Acta Paediatr 2007; 96: 1333-1337.

13. Lodrup Carlsen KC, Haland G, Devulapalli CS, et al. Asthma in every fifth child in 0slo, Norway: a 10-year follow up of a birth cohort study. Allergy 2006; 61: 454-460.

14. Skjønsberg $\mathrm{OH}$, Clench-Aas J, Leegaard J, et al. Prevalence of bronchial asthma in schoolchildren in Oslo, Norway. Comparison of data obtained in 1993 and 1981. Allergy 1995; 50: 806-810.

15. Gilliland FD, Berhane K, Islam T, et al. Obesity and the risk of newly diagnosed asthma in school-age children. Am J Epidemiol $2003 ; 158: 406-415$.

16. Castro-Rodriguez JA, Holberg CJ, Morgan WJ, et al. Increased incidence of asthmalike symptoms in girls who become overweight or obese during the school years. Am J Respir Crit Care Med 2001; 163: 1344-1349.

17. Hancox RJ, Milne BJ, Poulton R, et al. Sex differences in the relation between body mass index and asthma and atopy in a birth cohort. Am J Respir Crit Care Med 2005; 171: 440-445.

18. Gold DR, Damokosh AI, Dockery DW, et al. Body-mass index as a predictor of incident asthma in a prospective cohort of children. Pediatr Pulmonol 2003; 36: 514-521.

19. Barr RG, Cooper DM, Speizer FE, et al. Beta(2)-adrenoceptor polymorphism and body mass index are associated with adult-onset asthma in sedentary but not active women. Chest 2001; 120: 1474-1479.

20. Åstrand PO, Rodahl K, Dahl HA, et al. Textbook of Work Physiology. Revised Edn. New York, McGraw-Hill, 2003.

21. Krahenbuhl GS, Skinner JS, Kohrt WM. Developmental aspects of maximal aerobic power in children. Exerc Sport Sci Rev 1985; 13: 503-538.

22. Noakes TD. Implications of exercise testing for prediction of athletic performance: a contemporary perspective. Med Sci Sports Exerc 1988; $20: 319-330$.

23. Myers J, Walsh D, Buchanan N, et al. Can maximal cardiopulmonary capacity be recognized by a plateau in oxygen uptake? Chest 1989; 96: $1312-1316$.

24. Myers J, Walsh D, Sullivan M, et al. Effect of sampling on variability and plateau in oxygen uptake. J Appl Physiol 1990; 68: 404-410.

25. Duncan GE, Howley ET, Johnson BN. Applicability of $V_{0_{2}}$, max criteria: discontinuous versus continuous protocols. Med Sci Sports Exerc 1997; $29: 273-278$.

26. Carlsen KH, Oseid S, Odden H, et al. The response to heavy swimming exercise in children with and without bronchial asthma. In: Oseid S, Carlsen KH, eds. Children and Exercise XIII. Champaign, Human Kinetics Publishers, Inc., 1989; pp. 351-360.

27. Gibson PB, Szimonisz SM, Rowland TW. Rowing ergometry for assessment of aerobic fitness in children. Int J Sports Med 2000; 21: 579-582.

28. Klein AA. Pediatric exercise testing. Pediatr Ann 1987; 16: 546-541.

29. Kang J, Chaloupka EC, Mastrangelo MA, et al. Physiological comparisons among three maximal treadmill exercise protocols in trained and untrained individuals. Eur J Appl Physiol 2001; 84: 291-295.

30. Fredriksen PM, Ingjer F, Nystad W, et al. Aerobic endurance testing of children and adolescents-a comparison of two treadmill-protocols. Scand J Med Sci Sports 1998; 8: 203-207.

31. Day JR, Rossiter HB, Coats EM, et al. The maximally attainable V0 during exercise in humans: the peak vs. maximum issue. J Appl Physiol 2003; 95: 19011907.

32. Rossiter HB, Kowalchuk JM, Whipp BJ. A test to establish maximum $\mathrm{O}_{2}$ uptake despite no plateau in the $\mathrm{O}_{2}$ uptake response to ramp incremental exercise. $\mathrm{J}$ Appl Physiol 2006; 100: 764-770.

33. Cooper DM. Rethinking exercise testing in children: a challenge. Am J Respir Crit Care Med 1995; 152: 1154-1157. 
34. Stensrud T, Carlsen KH. Can one single test protocol for provoking exercise-induced bronchoconstriction also be used for assessing aerobic capacity? Clin Respir J 2008; 2: 47-53.

35. Hermansen L. Oxygen transport during exercise in human subjects. Acta Physiol Scand Suppl 1973; 399: 1-104.

36. Crapo RO, Casaburi R, Coates AL, et al. Guidelines for methacholine and exercise challenge testing-1999. This official statement of the American Thoracic Society was adopted by the ATS Board of Directors, July 1999. Am J Respir Crit Care Med 2000; 161: 309-329.

37. Stromme SB, Ingjer F, Meen HD. Assessment of maximal aerobic power in specifically trained athletes. J Appl Physiol 1977; 42: 833-837.

38. Gibson TM, Harrison MH, Wellicome RM. An evaluation of a treadmill work test. Br J Sports Med 1979; 13: 6-11.

39. Gibson GJ. Pulmonary hyperinflation: a clinical overview. Eur Respir J 1996; 9: 2640-2649.

40. Stensrud T, Berntsen S, Carlsen KH. Exercise capacity and exercise-induced bronchoconstriction (EIB) in a cold environment. Respir Med 2007; 101: 1529-1536.

41. Stensrud T, Berntsen S, Carlsen KH. Humidity influences exercise capacity in subjects with exercise-induced bronchoconstriction (EIB). Respir Med 2006; 100: 1633-1641.

42. Gibson GJ. Obesity, respiratory function and breathlessness. Thorax 2000; 55: Suppl.1, S41-S44.

43. Stensrud T, Carlsen KH. Exercise induced bronchoconstriction among athletes. Am J Respir Crit Care Med 2004; 169: A694.

44. Dempsey JA, Hanson PG, Henderson KS. Exercise-induced arterial hypoxaemia in healthy human subjects at sea level. J Physiol 1984; 355: 161-175.

45. Powers SK, Williams J. Exercise-induced hypoxaemia in highly trained athletes. Sports Med 1987; 4: 46-53.

46. Powers SK, Lawler J, Dempsey JA, et al. Effects of incomplete pulmonary gas exchange on $\mathrm{Vo}_{2}, \mathrm{maX}$. J Appl Physiol 1989; 66: 2491-2495.

47. Hopkins SR, Schoene RB, Henderson WR, et al. Intense exercise impairs the integrity of the pulmonary blood-gas barrier in elite athletes. Am J Respir Crit Care Med 1997; 155: 1090-1094.

48. Dempsey JA, Johnson BD, Saupe KW. Adaptations and limitations in the pulmonary system during exercise. Chest 1990; 97: Suppl., 81S-87S.

49. Johnson BD, Reddan WG, Pegelow DF, et al. Flow limitation and regulation of functional residual capacity during exercise in a physically active aging population. Am Rev Respir Dis 1991; 143: 960-967.

50. Dempsey JA, Johnson BD, Saupe KW. Adaptations and limitations in the pulmonary system during exercise. Chest 1990; 97: Suppl., 81S-87S.

51. Strauss RH, McFadden ER Jr, Ingram RH Jr, et al. Enhancement of exercise-induced asthma by cold air. N Engl J Med 1977; 297: 743-747.

52. Anderson SD, Schoeffel RE, Follet R, et al. Sensitivity to heat and water loss at rest and during exercise in asthmatic patients. Eur J Respir Dis 1982; 63: 459-471.

53. Bar-0r 0, Neuman I, Dotan R. Effects of dry and humid climates on exercise-induced asthma in children and preadolescents. J Allergy Clin Immunol 1977; 60: 163-168.

54. Carlsen KH, Engh G, Mørk M, et al. Cold air inhalation and exercise-induced bronchoconstriction in relationship to metacholine bronchial responsiveness. Different patterns in asthmatic children and children with other chronic lung diseases. Respir Med 1998; 92: 308-315.

55. Kallings LV, Emtner M, Backlund L. Exercise-induced bronchoconstriction in adults with asthma-comparison between running and cycling and between cycling at different air conditions. Ups J Med Sci 1999; 104: 191-198.

56. Eschenbacher WL, Moore TB, Lorenzen TJ, et al. Pulmonary responses of asthmatic and normal subjects to different temperature and humidity conditions in an environmental chamber. Lung 1992; 170: 51-62.

57. Sandsund M, Faerevik H, Reinertsen RE, et al. Effects of breathing cold and warm air on lung function and physical performance in asthmatic and nonasthmatic athletes during exercise in the cold. Ann NYAcad Sci 1997; 813: 751-756.

58. Denjean A, Canet E, Praud JP, et al. Hypoxia-induced bronchial responsiveness in awake sheep: role of carotid chemoreceptors. Respir Physiol 1991; 83: 201-210.

59. Denjean A, Roux C, Herve P, et al. Mild isocapnic hypoxia enhances the bronchial response to methacholine in asthmatic subjects. Am Rev Respir Dis 1988; 138: 789-793.

60. Saito H, Nishimura M, Shinano H, et al. Effect of mild hypoxia on airway responsiveness to methacholine in subjects with airway hyperresponsiveness. Chest 1999; 116: 1653-1658.

61. Alberts WM, Colice GC, Hammond MD, et al. Effect of mild hypoxemia on bronchial responsiveness. Ann Allergy 1990; 65: 189-193.

62. Martin D, $0^{\prime}$ Kroy J. Effects of acute hypoxia on the $V_{0_{2}}$, max of trained and untrained subjects. J Sports Sci 1993; 11: 37-42.

63) Lawler J, Powers SK, Thompson D. Linear relationship between $V_{0_{2}}$, max and $V_{0_{2}}$, max decrement during exposure to acute hypoxia. J Appl Physiol 1988; 64: 1486-1492.

64. Quirion A, Laurencelle L, Paulin L, et al. Metabolic and hormonal responses during exercise at 20 degrees, 0 degrees and -20 degrees C. Int J Biometeorol 1989; 33: 227-232.

65. Sandsund M, Sue-Chu M, Helgerud J, et al. Effect of cold exposure (-15 degrees $C$ ) and salbutamol treatment on physical performance in elite nonasthmatic cross-country skiers. Eur J Appl Physiol Occup Physiol 1998; 77: 297-304.

66. Claremont AD, Nagle F, Reddan WD, et al. Comparison of metabolic, temperature, heart rate and ventilatory responses to exercise at extreme ambient temperatures (0 degrees and 35 degrees C). Med Sci Sports 1975; 7: 150-154.

67. Berntsen S, Stensrud T, Ingjer F, et al. Asthma in medium altitude - exercise-induced bronchoconstriction in hypobaric environment in subjects with asthma. Allergy 2005; 60: 1308-1311.

68. Peltonen JE, Tikkanen HO, Rusko HK. Cardiorespiratory responses to exercise in acute hypoxia, hyperoxia and normoxia. Eur J Appl Physiol 2001; 85: 82-88.

69. Dempsey JA, Wagner PD. Exercise-induced arterial hypoxemia. J Appl Physiol 1999; 87: 1997-2006. 